\title{
Viscous Aerodynamic Shape Optimization with Installed Propulsion Effects
}

\author{
Christopher M. Heath ${ }^{*}$ and Jonathan A. Seidel ${ }^{\dagger}$ \\ NASA John H. Glenn Research Center at Lewis Field, Cleveland, OH 44135 \\ and \\ Sriram K. Rallabhandi \\ NASA Langley Research Center, Hampton, VA 23666
}

\begin{abstract}
Aerodynamic shape optimization is demonstrated to tailor the under-track pressure signature of a conceptual low-boom supersonic aircraft. Primarily, the optimization matches the near-field pressure disturbances induced by propulsion integration effects to a prescribed low-boom target. For computational efficiency, gradient-based optimization is used and coupled to the discrete adjoint formulation of the Reynolds-averaged Navier Stokes equations. The engine outer nacelle, nozzle, and vertical tail fairing are axi-symmetrically parameterized, while the horizontal tail is shaped using a wing-based parameterization. Overall, 48 design variables are coupled to the geometry and used to deform the outer mold line. During the design process, an inequality drag constraint is enforced to avoid major compromise in aerodynamic performance. Linear elastic mesh morphing is used to deform the volume grid between design iterations. The optimization is performed at Mach 1.6 cruise, assuming standard day altitude conditions at $51,707-\mathrm{ft}$. To reduce uncertainty, a coupled thermodynamic engine cycle model is employed that captures installed inlet performance effects on engine operation.
\end{abstract}

\section{Nomenclature}

$\begin{array}{ll}\text { AFLR } & =\text { advancing-front local reconnection } \\ A I P & =\text { aerodynamic interface plane } \\ C F D & =\text { computational fluid dynamics } \\ C_{L} & =\text { lift coefficient } \\ C F L & =\text { Courant-Friedrichs-Lewy } \\ F U N 3 D & =\text { Fully Unstructured Navier-Stokes 3-D } \\ \text { GMRES } & =\text { generalized minimum residual } \\ \text { GTOW } & =\text { gross take-off weight } \\ P L d B & =\text { perceived loudness level (decibels) } \\ R A N S & =\text { Reynolds-averaged Navier-Stokes } \\ p & =\text { static pressure } \\ S N O P T & =\text { sparse non-linear optimizer } \\ S Q P & =\text { sequential quadratic programming } \\ W & =\text { mass flow rate }\end{array}$

\section{Introduction}

$\mathrm{D}$ ue to the growing market opportunity for commercial supersonic air transportation, new design strategies are being explored to produce high speed aircraft that are not only economically viable, but also satisfy stringent regulations that currently ban overland supersonic flight. Past studies ${ }^{1-4}$ have demonstrated that moderate attenuation

\footnotetext{
* Aerospace Engineer, Propulsion Systems Analysis Branch.

${ }^{\dagger}$ Senior Aerospace Engineer, Propulsion Systems Analysis Branch.

* Aerospace Engineer, Aeronautics Systems Analysis Branch.
} 
in the propagated sonic boom loudness of aircraft can be achieved through aerodynamic tailoring. However, the majority of research to date has neglected detailed propulsion effects, sacrificing the accuracy of inlet spillage and nozzle exhaust jets in low-boom design iterations. In addition, conceptual design often omits viscous aerodynamic effects which can have a detrimental impact on installed propulsive performance and vehicle sonic boom loudness levels. For example, prior research ${ }^{5-7}$ has indicated that adding viscous or propulsion effects into a pre-optimized low-boom airframe signature can greatly compromise sonic boom performance.

The primary objective of this study is to demonstrate viscous aerodynamic shape optimization on a low-boom aircraft to recover sonic boom performance margin compromised during propulsion-airframe integration. The most common low-boom design paradigm to date uses the airframe to shield the propulsion system, minimizing the engine contribution to the vehicle sonic boom signature. This often involves above-wing mounted or embedded engine installations that ingest boundary layer flow, potentially compromising inlet recovery and degrading engine performance. Other efforts have sought to minimize the impact of the propulsion system on sonic boom by enclosing it in a high-flow nacelle bypass duct. $^{8}$ The purpose of the duct is to aerodynamically fair over auxiliary mounted accessory drives while reducing external cowl and nozzle boat-tail angles. ${ }^{8}$ While this can decrease the isolated engine pressure field disturbances, it comes with the penalty of increased pressure drag from the bypass nacelle. Furthermore, there is no assurance that such a quiet supersonic engine will remain low-boom once integrated with an airframe; but it can offer more design latitude for propulsion integration. Taking a counterapproach to the former, this study explores a new paradigm where installed engine effects are leveraged during design to favorably impact sonic boom performance. Essentially, the propulsion effects are fully coupled and designed into the vehicle to optimize system sonic boom performance.

A secondary outcome of this research is to fully characterize off-design inlet operation, enhancing inlet feasibility and inlet/engine airflow matching. To accomplish this, installed inlet recovery characteristics were computed throughout the flight envelope and directly coupled to a thermodynamic engine model. The actual inlet recovery operating curves were used to refine the engine throttle setting, level of thrust augmentation, nozzle stagnation flow conditions and nozzle actuation setting. This secondary pursuit gives a high level of design closure that reduces the optimized sonic boom vehicle loudness uncertainty due to powered engine effects.

This paper proceeds with discussion of the baseline vehicle configuration and methods for performing aerodynamic shape optimization in Section II. Section III details the propulsion-airframe integration approach, including optimization and comprehensive characterization of installed inlet performance. Description of the inlet/engine airflow matching process is then described. In Section IV, results from the adjoint-based optimization process to minimize sonic boom loudness are presented, followed by conclusions and recommendations for future work.

\section{Problem Definition}

\section{A. Baseline Vehicle Configuration Description}

The baseline vehicle with integrated propulsion system is depicted in Fig. 1. The low-boom airframe was reverse-engineered from [4], with the axisymmetric spike inlet and propulsion flow path down-selected from the trade study in [7]. Modifications to the inlet were made for this study to improve off-design operation and are reported in Section III-A.

The engine core paired with the inlet is representative of a General Electric F404-GE-402 afterburning turbofan, throttled to produce approximately $4500-\mathrm{lbf}$ thrust at cruise with partial afterburner. As a result of engine installation in [7], vehicle sonic boom loudness was moderately compromised across the entire boom carpet. This study uses aerodynamic shape optimization to recover a portion of the sacrificed sonic boom loudness margin lost during engine integration.

The aircraft design cruise point for optimization is Mach 1.6 at a flight altitude of 51,707-ft. The cruise $C_{L}$ target is 0.065 , which corresponds to a 21,000-lbf gross take-off weight (GTOW). In [7], the vehicle cruise angle of attack was adjusted to match the target $C_{L}$. Similarly, the nozzle gross thrust was tailored to balance overall drag forces (vehicle drag plus inlet ram drag) and match the engine mass flow rate consistent with the thermodynamic engine cycle model. Nozzle outflow boundary conditions at the augmentor exit were provided from coupled engine thermodynamic cycle analysis. The coupling process is detailed in sections III-B and III-C. 


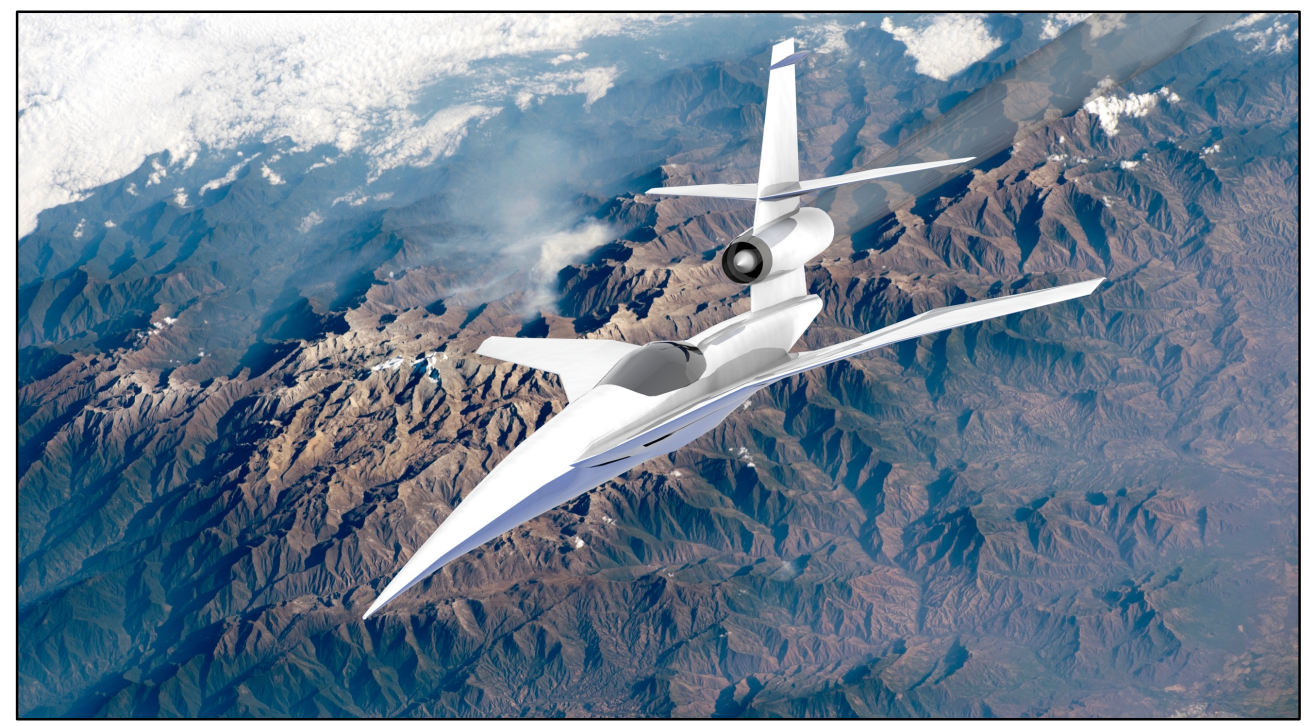

Figure 1. Low-boom flight demonstrator concept.

\section{B. Sonic Boom Optimization Problem}

Starting from the conceptual reference vehicle in Fig. 1, the engine nacelle, nozzle, horizontal tail, and aerodynamic tail fairing were parameterized and tailored to match a target pressure signature located five vehicle body lengths directly under-track. The near-field pressure target focused specifically on improving the vehicle signature aft of the wing trailing edge. The target signature was reverse-engineered using an adjoint-based $\operatorname{method}^{9}$ to yield a favorable loudness objective of 72.7 PLdB when propagated to a ground observer. Propagation mechanics accounted for signal attenuation attributed to atmospheric nonlinearities, thermo-viscous absorption and molecular relaxation. Low-boom optimization was performed using the Fully Unstructured Navier-Stokes 3-D (FUN3D) ${ }^{10}$ computational fluid dynamics (CFD) software. The framework includes a three-dimensional, node-based, NavierStokes flow solver for unstructured mixed-element grids. The aerodynamic solver is coupled with a discrete adjoint methodology which provides analytic sensitivities to support gradient-based shape optimization and grid adaptation. Given the high computational cost of Reynolds-averaged Navier Stokes (RANS) analysis for design, gradient-based optimization was a practical requirement given computational resource limitations.

The formal low-boom optimization problem was formulated as:

Minimize:

Subject to:

$$
f=\sum_{i=1}^{N}\left(\left.\frac{p}{p_{\infty}}\right|_{i}-\left.\frac{p}{p_{\infty}}\right|_{i} ^{*}\right)^{2}
$$

$$
0.0<C_{D}<C_{D, \text { Limit }}
$$

where $f$ is the objective function defined as the sum of squared differences between the local static pressure ratio $\left.\frac{p}{p_{\infty}}\right|_{i}$ along a linear pressure field sensor at point $i$ and a pre-defined low-boom feasible target static pressure ratio $\left.\frac{p}{p_{\infty}}\right|_{i} ^{*}$. In Eq. 1, $N$ corresponds to 1000 points uniformly sampled from the CFD near-field solution. An explicit constraint was also specified to restrict the airframe drag coefficient, $C_{D}$, from increasing by more than $1.5 \%$.

To control the optimization and match the target pressure distribution, the Sparse, Nonlinear Optimizer $(\mathrm{SNOPT})^{11}$ was used, which leveraged the Sequential Quadratic Programming (SQP) method. During each major iteration, a Quadratic Programming (QP) sub-problem is solved to determine an updated search direction. The SQP algorithm implements a smooth augmented Lagrangian merit function with explicit provision for infeasibility in the original problem and QP subproblems. ${ }^{11}$ The Hessian of the Lagrangian is estimated using the limited memory quasi-Newton method. 


\section{Computational Domain Specification}

For near-field aerodynamic prediction, a faceted half-cylindrical core computational domain was constructed as depicted in Fig 2. The cylindrical boundary was approximated using 18 planar surfaces arranged parallel to the axis of rotation. Within the domain, the vehicle was rotated to the design angle of attack required at start of cruise to match vehicle weight. Unstructured meshes were constructed on all core grid surfaces using the commercial software Pointwise ${ }^{B}$. Anisotropic cells were used to resolve regions of high geometric surface curvature. The baseline surface grid contained on the order of 275,000 points. A sourcing model was introduced to resolve the nozzle plume and shock-plume interactions. An all-tetrahedral core volume grid was generated using the advancingfront local reconnection (AFLR3) ${ }^{12}$ algorithm. All viscous volume layers were resolved down to a $\mathrm{y}^{+}$resolution less than 1 . Volume meshes for the core domain contained approximately 60 million elements. A sample symmetry plane view of the core grid is shown in Fig. 3. Given challenges with parameterizing and computing analytic geometric sensitivities along component intersections, the vertical tail was removed for optimization. Given the size and vertical orientation, initial sensitivity analysis indicated removal of the vertical tail had negligible impact on the local pressure field at a distance of five body lengths below the aircraft.

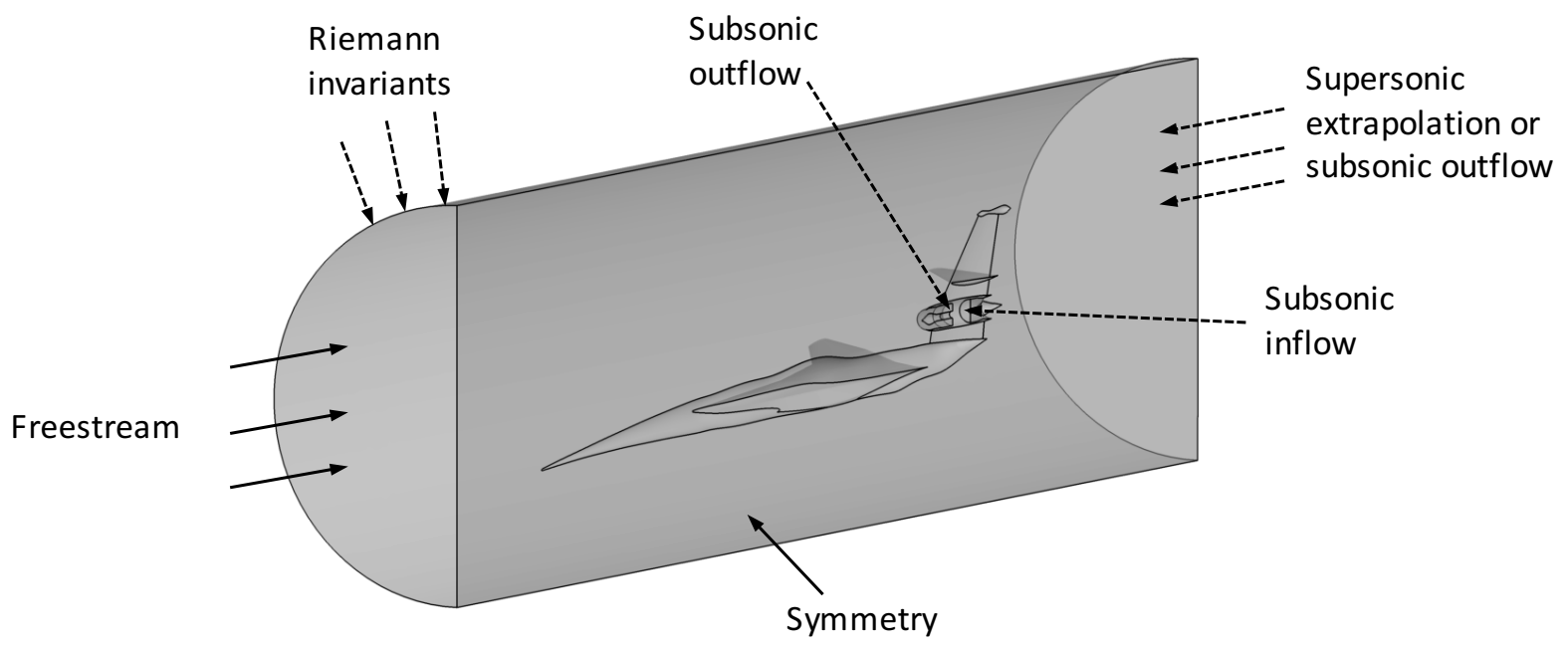

Figure 2. Computational core domain for the baseline aircraft.

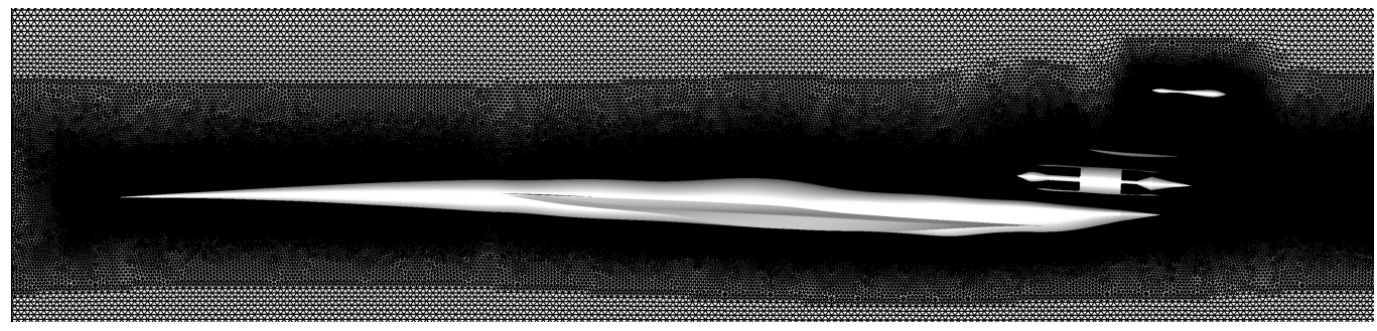

Figure 3. Unstructured core mesh produced using Pointwise and AFLR3 software.

A collar grid was extruded to efficiently extend the core domain a distance of six body lengths from the vehicle. To form a Mach-aligned outer collar grid, the approximate cylindrical boundary cells of the core grid were extruded radially outward and swept to align with the freestream Mach angle using the Inflate ${ }^{13}$ tool. Similar mesh construction processes for sonic boom analysis are described in Refs. [14,15]. The collar grid contained 150 prism element layers with increased cell stretching away from the vehicle. A portion of the computational domain containing the core and collar grids is illustrated in Fig. 4. To improve robustness of the volume grid deformation mechanics during design optimization, the entire mesh was converted to all tetrahedral elements. The complete design grid contained $\sim 165$ million cells. 
Computational boundary conditions were assigned to all physical domains. A freestream condition enforcing Mach number and static reference conditions commensurate with 51,707-ft standard day altitude was specified at the upstream boundary. A Riemann invariant condition was specified on the approximate cylindrical near-field outer domain. For supersonic cases, an extrapolation boundary condition was prescribed on the downstream exit. For subsonic cases, a uniform static exit pressure boundary condition was applied. Uniform static back pressure was also assigned to simulate the engine fan condition, which is considered an efficient and conservative assumption. This uniform static pressure boundary was enforced one engine diameter downstream of the actual fan location to mitigate the potential influence on distortion and recovery values computed at the aerodynamic interface plane (AIP). Total temperature and pressure ratios with respect to freestream were used to simulate the nozzle inflow boundary. All physical aircraft surfaces were assigned a viscous no-slip condition.

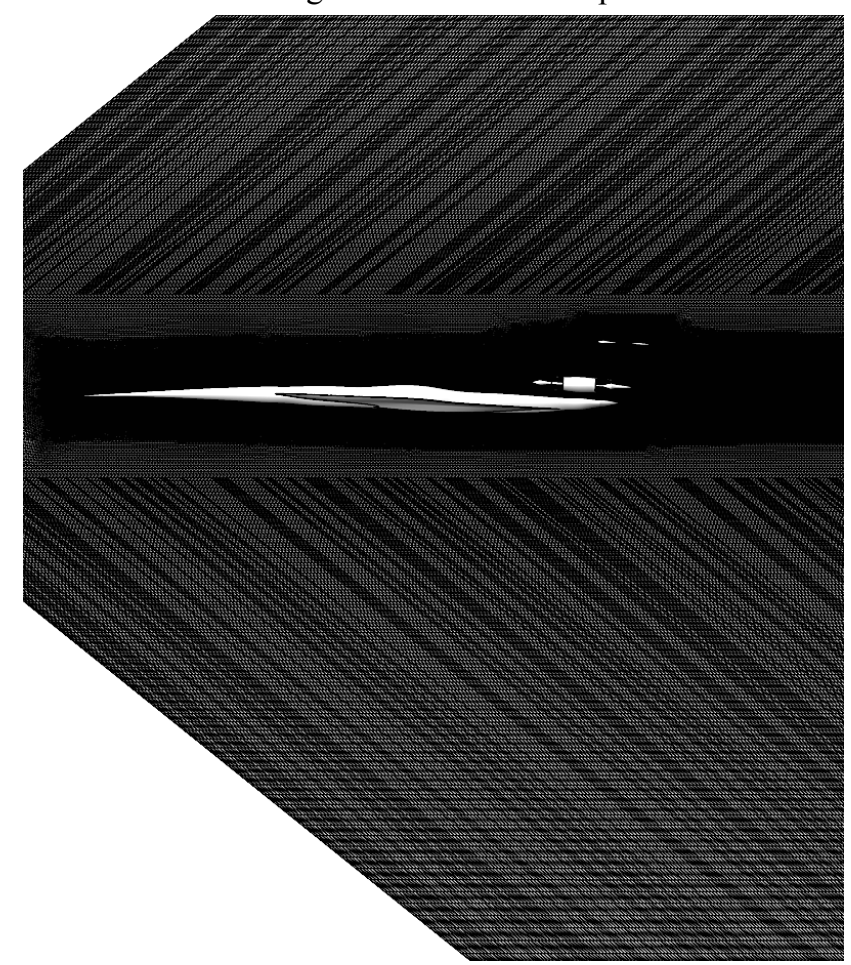

Figure 4. Combined core and swept collar mesh for near flowfield prediction.

\section{Geometry Parameterization}

The axisymmetric parameterization approach described in [16] was applied to deform and tailor the engine nacelle, nozzle plug and aerodynamic tail fairing to match the low-boom feasible off-body pressure target. Minor changes to the deformation scheme were made, including application of a rotation matrix to account for vehicle angle of attack. The discrete surface derivatives in Cartesian coordinates were also adjusted accordingly. Third-order B-splines were used to parameterize the surface mesh deformations, and offered a means to compute direct analytic sensitivities with respect to control point motion. Although the axisymmetric deformation approach used permits radial and axial control point perturbations, only radial motion was active during design. In previous work ${ }^{16}$, simultaneous axial and radial deformation of supersonic nozzle geometries with sharp feature angles was found to reduce robustness of the linear elasticity solution for volume grid deformation during design. For the engine nacelle, a total of nine radial design parameters were active and uniformly spaced over the length of the engine. The inlet leading edge and nozzle trailing edge locations were fixed. The aerodynamic tail fairing also used nine uniformly spaced control points with leading and trailing edge points fixed. The nozzle plug was parameterized using five active control points aft of the nozzle throat, permitting under- or over-expansion of the plume to reduce sonic boom loudness. The plug tip location was fixed. The wing-based parameterization tool MASSOUD ${ }^{17}$ was used to deform the horizontal tail cross-sectional shape, planform, twist and camber with 21 design control points mapped to the geometry at various span-wise locations. The free-form deformation tool BANDAIDS ${ }^{18}$ was used to parameterize changes to the aft fuselage cross sections with four active design control points. The total number of active geometry control points used for sonic boom optimization was 48. The region parameterized for design is called out in Fig. 5. 


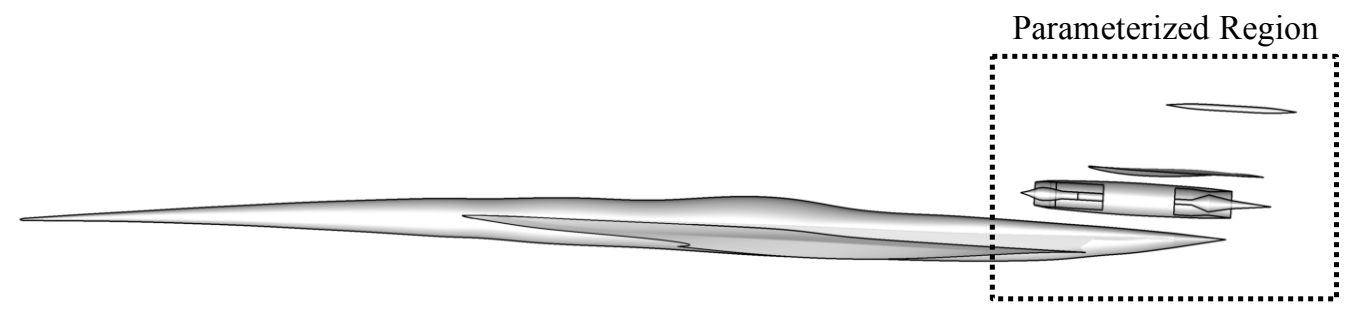

Figure 5. Initial vehicle profile with aft components parameterized for optimization.

\section{E. Flow and Adjoint Solvers}

All near-field aerodynamic solutions were computed using FUN3D. The flow solver uses a second-order accurate point-implicit method and accommodates convergence acceleration using scheduled Courant-FriedrichsLewy (CFL) number ramping. Cell interface fluxes were computed using the upwind inviscid scheme of Roe ${ }^{19}$. The one-equation Spalart-Allmaras ${ }^{20}$ model was coupled to the mean flow equations for turbulence closure.

Following convergence of the steady-state RANS equations, the set of discrete adjoint equations ${ }^{21-23}$ were solved using a dual-consistent time-marching method. ${ }^{24,25}$ A primary advantage of the adjoint approach is that solution sensitivities can be obtained for an objective function with respect to many design variables at a computational cost comparable to that of a single flow solution.

During design optimization, volume mesh displacements were computed by solving the finite volume formulation of the linear elasticity equations ${ }^{26}$ using the Generalized Minimum Residual (GMRES) ${ }^{27}$ algorithm. Elements near moving wall boundaries were stiffened to conform with prescribed surface deflections. The majority of grid distortion was absorbed by interior volume cells away from solid deforming boundaries.

\section{Propulsion Airframe Integration}

\section{A. Adjoint-Based Installed Inlet Optimization}

To enhance engine model fidelity, the axisymmetric spike inlet from [7] was adopted and modified with an increased leading-edge lip radius to better accommodate low-speed and cross-wind operation. In addition, an in-line translating auxiliary door was introduced to meet engine mass flow demand during static takeoff and climb-out. The inlet sizing and design code SUPIN ${ }^{28}$ was used to modify the 3-D axisymmetric inlet flow lines and spike center body profile described in [7]. The SUPIN code computes 1-D flowfield conditions from freestream to the engine face using a combination of analytical, numerical and empirical aerodynamic models. Corrections can be included to reconcile boundary layer and total pressure loss effects. SUPIN internally tracks normal and oblique shock losses, spillage, wave drag and bleed. Since SUPIN is a low-fidelity design tool and only computes 1-D flow conditions, it has limited ability to account for non-uniformities in approach flow or installation effects. Iteration with 3-D CFD is necessary to ensure the SUPIN design and sizing process yields an inlet with optimal installed performance.

The aft and above-fuselage mounted engine for the reference aircraft in this study experiences a number of installation effects unaccounted for during SUPIN inlet sizing and design. For example, the local inlet approach Mach number is $\sim 1.5 \%$ above the vehicle freestream speed and exhibits a velocity gradient due to boundary layer growth along the fuselage. These approach flow variations contribute to non-optimal installed inlet recovery and engine distortion at cruise. To recover total pressure losses from installation, reduce inlet spillage, and minimize distortion, gradient-based optimization of the aerodynamic spike center body was first performed. The aerodynamic spike was axi-symmetrically parameterized using nine uniformly spaced radial shape control variables and tailored using the FUN3D adjoint-based design optimization suite. The objective function for inlet optimization was to maximize installed inlet mass flow rate at the cruise point (i.e. minimize spillage). Similar approaches to inlet optimization have been reported for supersonic and hypersonic applications in Refs. [29-31].

Figure 6 compares the initial inlet geometry designed using SUPIN against the optimized variant near the critical operating point. Preceding optimization, the normal shock is positioned with a notable stand-off distance from the supersonic cowl lip and the inlet is operating sub-critical. The original center body flow turning angle near the throat is overly aggressive, causing flow acceleration after the terminal shock and recompression through a second weak internal shock. This mixed internal and external compression compromises the inlet total pressure recovery and actual capture mass flow rate. Following optimization, the terminal shock stand-off distance is greatly minimized, indicating less external flow spillage. In addition, the flow is not accelerated internally beyond sonic, which improves total pressure recovery as shown by the cane curves plotted in Fig. 7. 

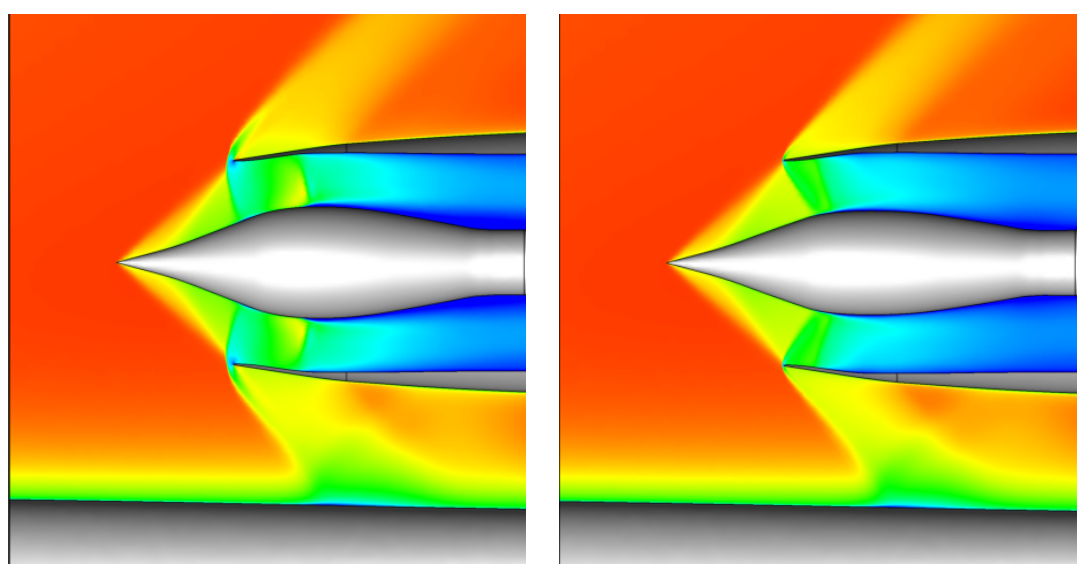

Mach No.
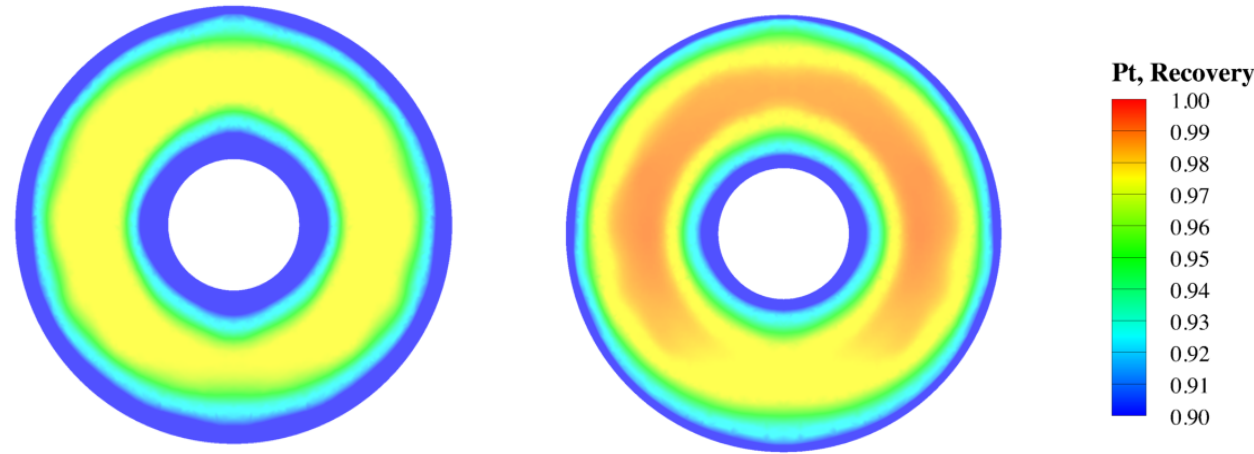

Figure 6. (Left) Baseline inlet flowfield at cruise. (Right) Inlet centerbody redesigned using adjoint-based optimization to minimize spillage.

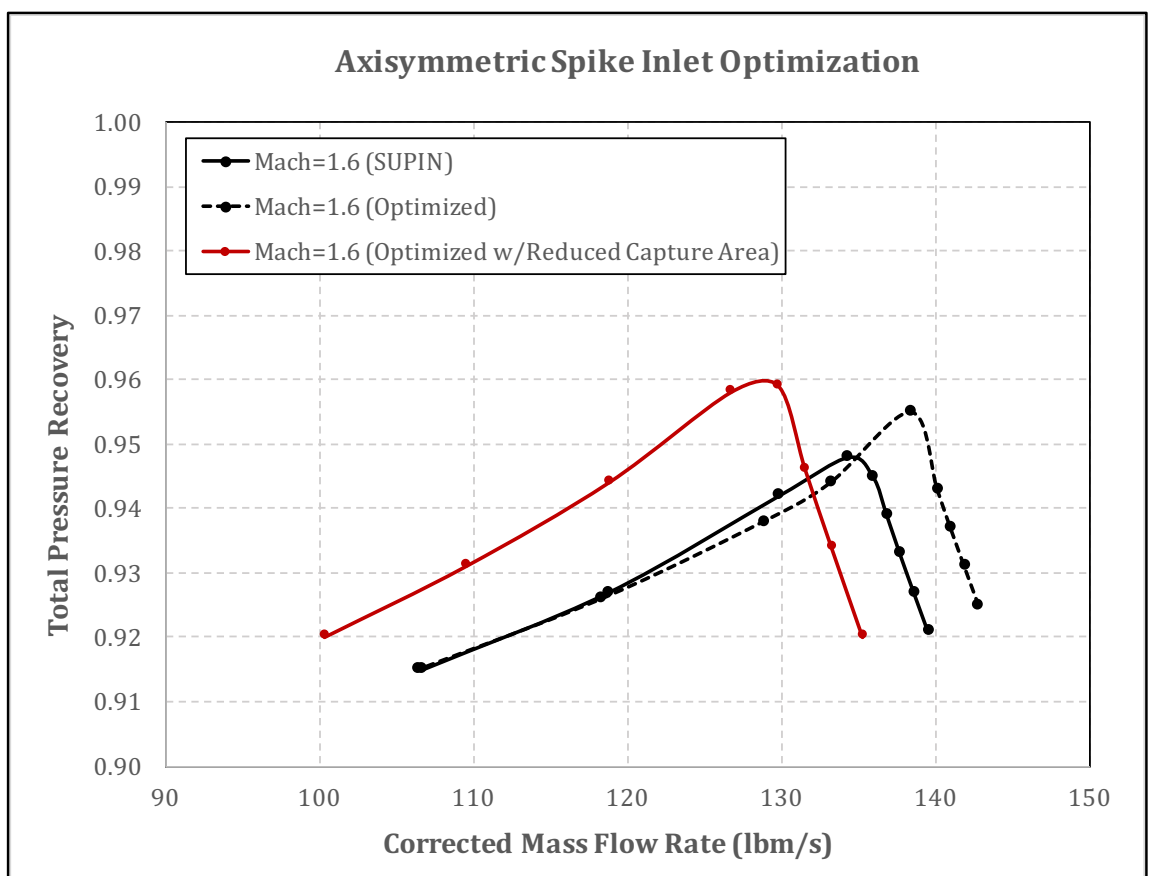

Figure 7. Characteristic cane curves for the installed SUPIN inlet design, compared against a RANS-optimized inlet. Also plotted is a revision to the RANS-optimized design to better match the engine flow demand at cruise. 
As a downside to the optimization, the increased pressure recovery coupled with the larger corrected mass flow rate delivered by the optimized inlet exceeds the F404 engine core mass flow demand at cruise by a significant margin $(\sim 8 \%)$. Rather than introduce spillage and operate highly subcritical, the inlet capture area was subsequently downsized by reducing the cowl diameter at the inlet lip. This capture area reduction resulted in a final inlet design which captured less excess flow and offered $\sim 96 \%$ critical peak recovery near the engine matched operating corrected flow rate $(\sim 130-1 \mathrm{bm} / \mathrm{s})$. The inlet with optimized centerbody and revised inlet capture area provides $\sim 1.8 \%$ better recovery over the SUPIN baseline inlet design. This final design also serves as a balanced compromise over the engine operating range; it provides up to $1.5 \%$ excess flow to the engine near cruise which can be used for component cooling, and is just undersized through transonic, meaning limited recovery performance is sacrificed at off-design operation.

\section{B. Inlet Performance Map Generation}

Installed inlet recovery curves were computed using full-vehicle RANS CFD simulations over a representative flight trajectory. Inlet characteristics were obtained at Mach numbers between 0.4 and 0.6 with auxiliary doors in the open and closed positions to select a feasible door transition point. Contours of total pressure recovery are plotted in Fig. 8 at select points along the flight trajectory to demonstrate installed inlet off-design operation. Note that at Mach 1.6, the inlet is positioned just outside the low momentum boundary layer flow along the aft fuselage. SAE ARP-1420 inlet distortion descriptors were also computed based on a standard 40-probe AIP rake for each cane curve, and used to define engine distortion limits. The result of this effort was the installed inlet performance maps in Figs. 9 and 10 that supplied inlet recoveries to the engine cycle model using an interpolated table lookup approach. This map was the result of $\sim 160$ independent RANS CFD simulations of the full aircraft configuration with various auxiliary door positions and differing flight attitudes along the trajectory.
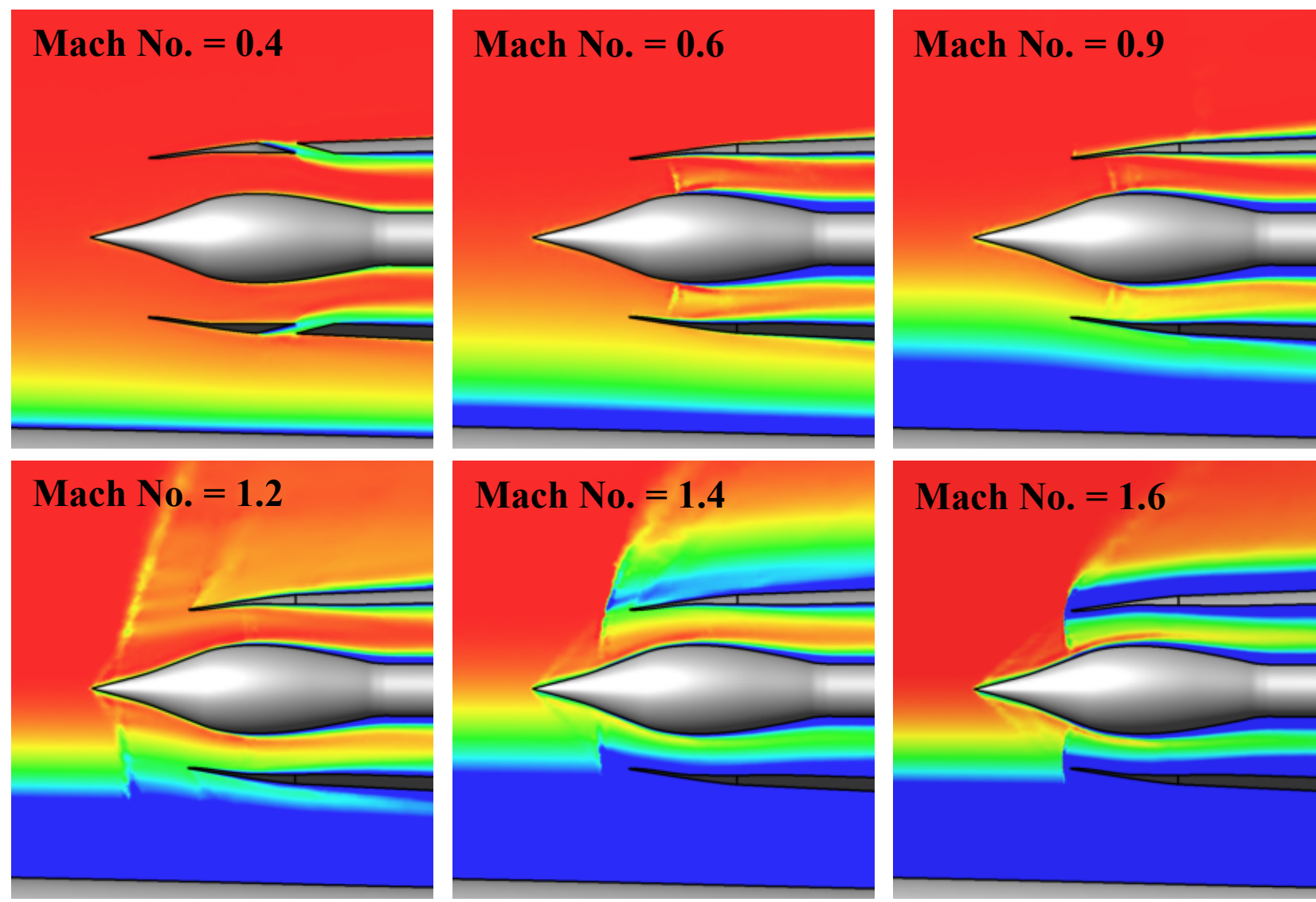

Pt, Recovery: $\begin{array}{llllll}0.95 & 0.96 & 0.97 & 0.98 & 0.99 & 1.00\end{array}$

Figure 8. Near-operating point total pressure recovery plots at various conditions over the flight envelope.

American Institute of Aeronautics and Astronautics 


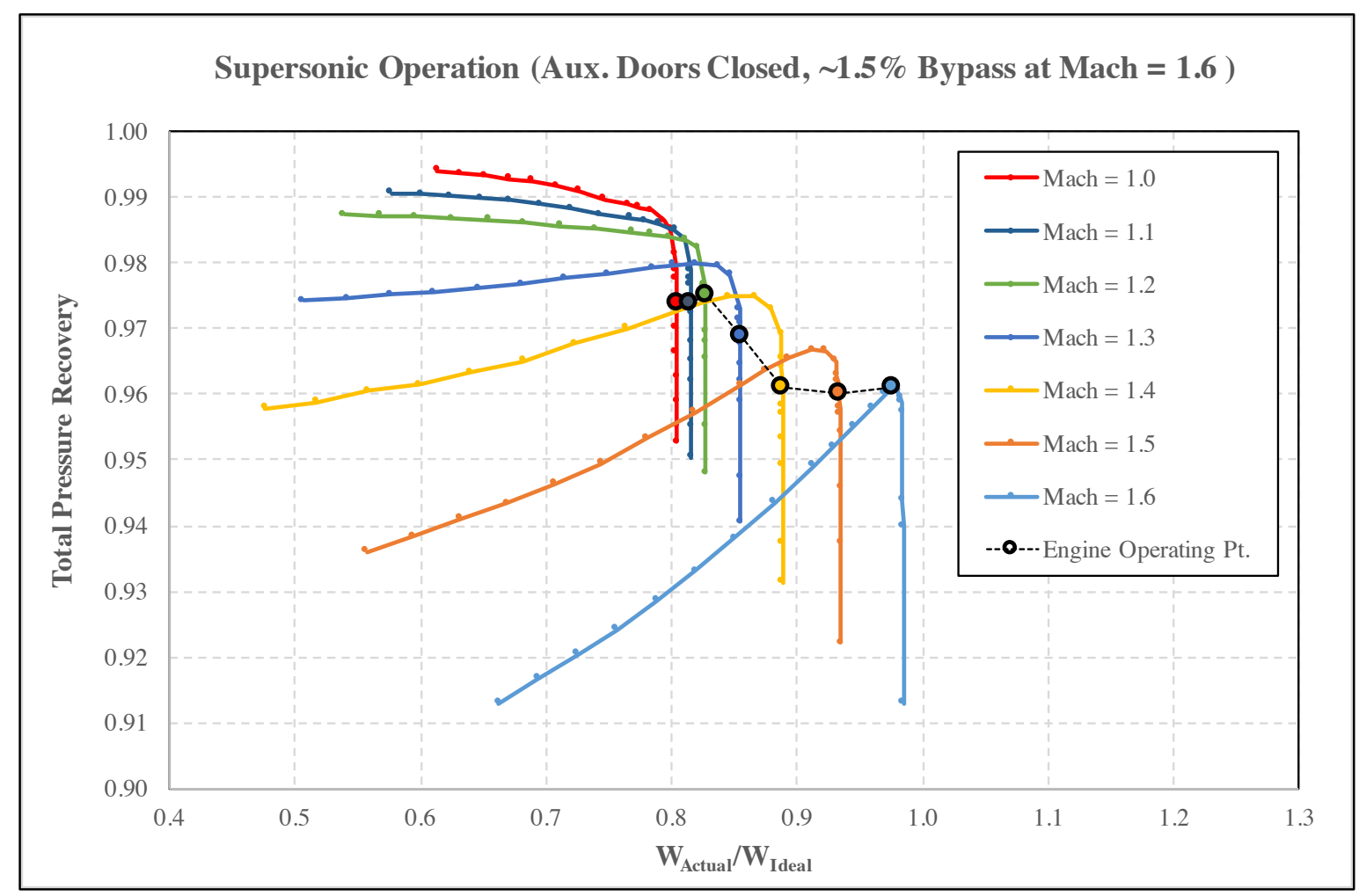

Figure 9. Installed supersonic inlet characteristics computed using RANS CFD.

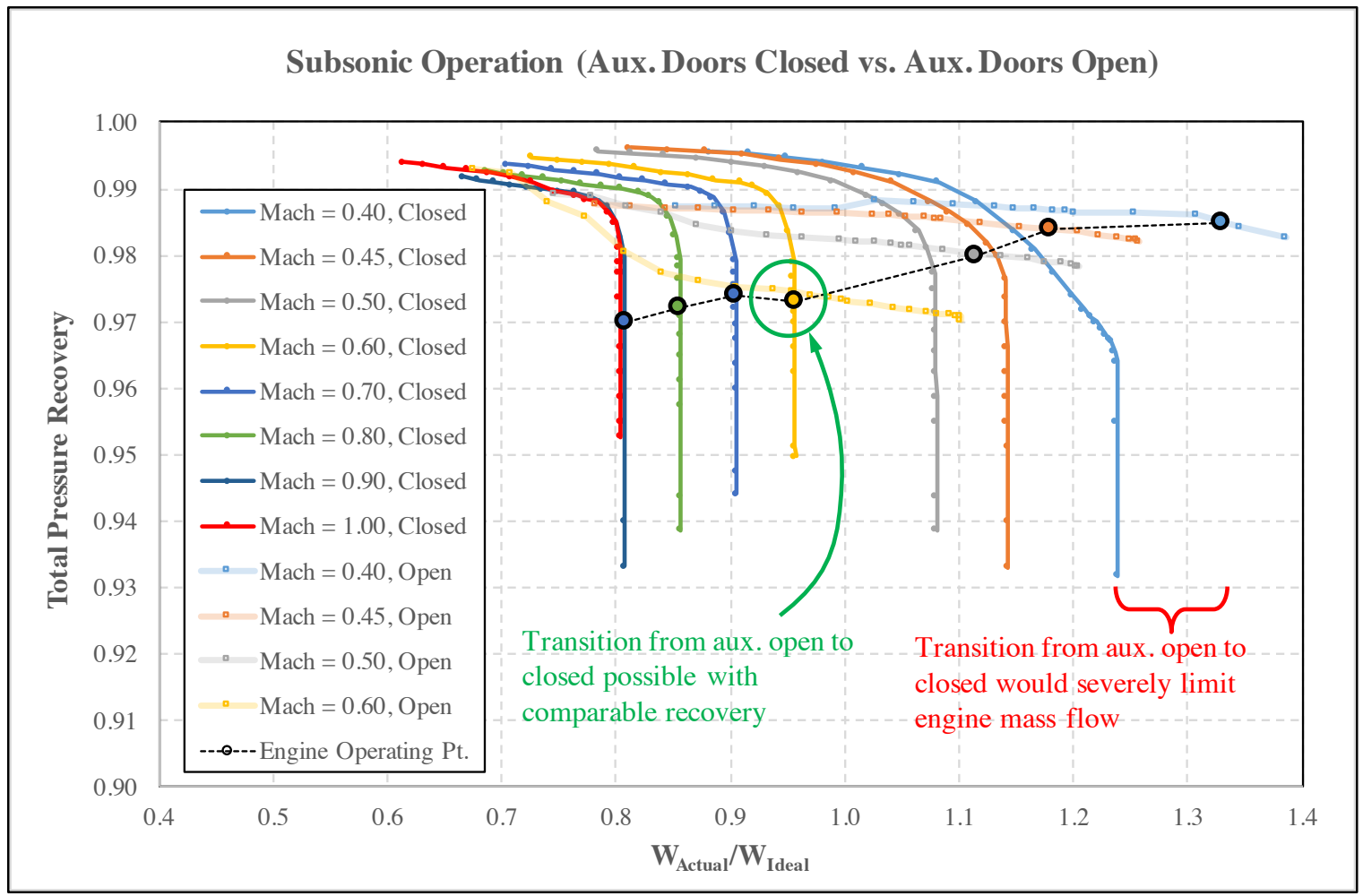

Figure 10. Installed subsonic inlet characteristics computed using RANS CFD.

American Institute of Aeronautics and Astronautics 


\section{Inlet/Cycle/Nozzle Coupling and Operating Schedule}

Inlet/engine matching and computation of the installed 1-D propulsion performance was executed using traditional thermodynamic cycle analysis combined with aero-mechanical design. For this study, a pre-existing NASA model of the General Electric F404-GE-402 afterburning turbofan engine was leveraged. The NASA cycle model was reverse-engineered using the Numerical Propulsion System Simulation (NPSS) ${ }^{32}$ code and calibrated to match manufacturer engine data available within the public domain ${ }^{33,34}$. The baseline inlet performance characteristics developed for the NPSS model were replaced with the custom table-based inlet performance map derived from the 3-D CFD-generated database shown in Figs. 9 and 10. The inlet performance characteristics were used to impose installed inlet total pressure recoveries, mass flow rates and distortion limits for revising the installed F404 engine operation. Similar to the inlet, the reference F404 nozzle was replaced with a custom plug nozzle, considered a practical low-boom solution and more traceable to future commercial supersonic transport aircraft. While this study did not address complete nozzle kinematics for off-design operation, the nozzle flow lines at cruise were established to ensure engine mass flow continuity, while also matching nozzle stagnation conditions from the thermodynamic cycle. In addition, the engine cruise throttle setting was determined such that net aerodynamic and propulsive forces acting on the entire vehicle at cruise were negligible. An aero-mechanical flow-path diagram of the NASA F404 NPSS model is depicted in Fig. 11.

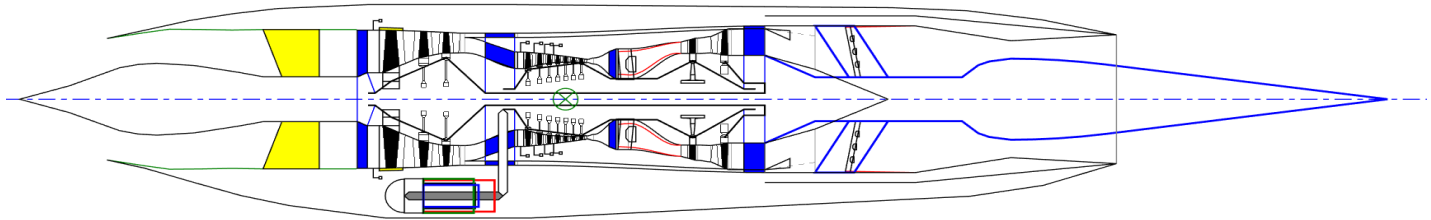

Figure 11. NASA reverse-engineered F404 flow path from aero-mechanical design.

When performing inlet/engine airflow matching over the complete flight profile, a challenge of ensuring consistent airflow lapse characteristic between the inlet and engine was encountered. In addition, the inlet performance characteristics exhibit a sharp reduction in total pressure recovery at flow rates above and below the peak recovery. This roll-off is most severe for the Mach 1.6 cane curve near the critical point and leaves only a narrow mass flow range in which optimal pressure recovery can be enjoyed. Guaranteeing engine operation near the desired corrected flow rate and at peak inlet recovery across the flight envelope was difficult to determine a-priori. Furthermore, inlet spillage as a means to reconcile airflow matching discrepancies near Mach 1.6 was considered undesirable. Not only does inlet spillage increase vehicle drag, but it can also disrupt the flowfield and have a detrimental impact on sonic boom. While inlet bleed is a better solution for improving viscous performance and distortion, it increases mechanical and operational complexity. Determining bleed patterns and schedules is considered beyond the scope of this conceptual study. Instead, a simpler solution was implemented which incorporated a small amount of engine bypass $(\sim 1.5 \%$ mass flow re-injected at the nozzle as nacelle bay purge $)$ that removed any inlet-captured flow in excess of the engine demand. Although the inlet/engine mass flows were matched near peak recovery as shown in Figs. 9 and 10, this bypass allowed the inlet to perform at the optimum cruise recovery without excess spillage or compromise in sonic boom.

Numerical convergence and robustness was another difficulty met while integrating the inlet performance map with the engine cycle model. This again was due to the sharp roll-off in the Mach 1.6 cane curve near the design point which caused convergence problems for the thermodynamic solver. It was deemed necessary to implement a refined approach in NPSS to assess installed performance modeling which enabled airflow-constrained operation of an engine as part of the direct convergence process. This refinement allowed inlet/engine operation with reduced or zero choke margin while improving overall numerical stability in concert with normal engine operating limits over the flight envelope. To further aid convergence, inlet total pressure recovery cane curves were scaled at Mach numbers intermediate to those supplied by CFD; thus, reducing potential interpolation issues near inlet choke.

Due to inlet flow constraints at low speed relative to engine demand, the auxiliary inlet was employed to deliver additional engine mass flow at higher total pressure recovery during takeoff and climb-out. Figure 10 describes the inlet total pressure recovery performance for operation with auxiliary doors in the open and closed position, along with the corresponding balanced engine operating point. Clearly, at low flight Mach numbers, operating the inlet with auxiliary doors open provides higher total pressure recovery at the preferred engine mass flow rates. Near Mach 0.6, the inlet total pressure recoveries are comparable with auxiliary doors in either the open or closed state at 
the desired engine mass flow rate. Figure 10 indicates that Mach 0.6 is a suitable transition point, above which the auxiliary doors should be closed to reduce nacelle drag. At Mach numbers beyond 0.6, the inlet still adequately satisfies the engine flow rate demand without significantly compromising total pressure recovery.

\section{Adjoint-Based Sonic Boom Optimization}

Starting from the baseline aircraft geometry described in [7] fitted with the optimized inlet from Section IIIA, the adjoint design capabilities of FUN3D were used to aerodynamically tailor the aircraft to match a low-boom target pressure signature located five body lengths directly under the vehicle. The near-field pressure waveforms were extrapolated to compute under-track ground signatures using sBOOM [35]. Usage assumed the ANSI S1.261995 standard atmosphere model and neglected atmospheric winds. Perceived loudness levels were computed using the approach detailed in [36].

During low-boom shape optimization, SNOPT completed 18 major iterations and terminated successfully after $\sim 35$ hours of wall clock time using 2100 compute cores. The merit function was decreased by $34.8 \%$, with optimality reduced five orders of magnitude. The explicit constraint on $C_{D}$ was active upon termination. The baseline and optimized geometries are shown overlaid in Fig. 12. The optimization introduced subtle surface curvature changes (compressions and expansions) to each of the designed components to neutralize the aft pressure waveforms in the engine vicinity. The size and volume of the vertical tail tip fairing was significantly reduced. The design intent behind the fairing was to extend and suppress the aft pressure field recompression. Optimization results suggest removal may be warranted without penalizing sonic boom loudness.

Figure 13 plots the baseline and optimized near-field pressure signatures against the low-boom near-field target. The pressure oscillations in the aft portion of the signature have been reduced and better match the prescribed target. Most notably, the leading expansion and recompression in the aft portion of the signature at an axial location near 227-m has been converted into smaller waveforms and suppressed. The smaller waveforms better coalesce and cancel when propagated to the ground.

The propagated ground signatures and perceived loudness levels are shown in Fig. 14. Similarly, the optimized aft signature profile at the ground more closely matches the target ground pressure distribution. The optimization yielded an overall 2.9 PLdB reduction in vehicle sonic boom loudness, and significant reduction in the loudness contribution from the engine and aft airframe components. Specifically, the perceived loudness contribution from the aft portion of the signature was reduced from 76.39 PLdB to $71.96 \mathrm{PLdB}$, which is a notable improvement. In the optimized configuration, the perceived loudness becomes dominated by the vehicle front end, indicating further loudness reduction could be achievable by parametrizing and reshaping the forward fuselage and wing.

As a result of optimizing for sonic boom loudness, a $\sim 1.5 \%$ compromise in airframe drag was tolerated. This was also accompanied by a $2.8 \%$ reduction in vehicle lift-to-drag ratio, assuming the same cruise angle of attack for the baseline and optimized configurations.

Symmetry plane pressure field contours are plotted in Fig. 15. Of note is the strong expansion features in the aft end of the vehicle signature that have been suppressed by the aerodynamic tailoring process.

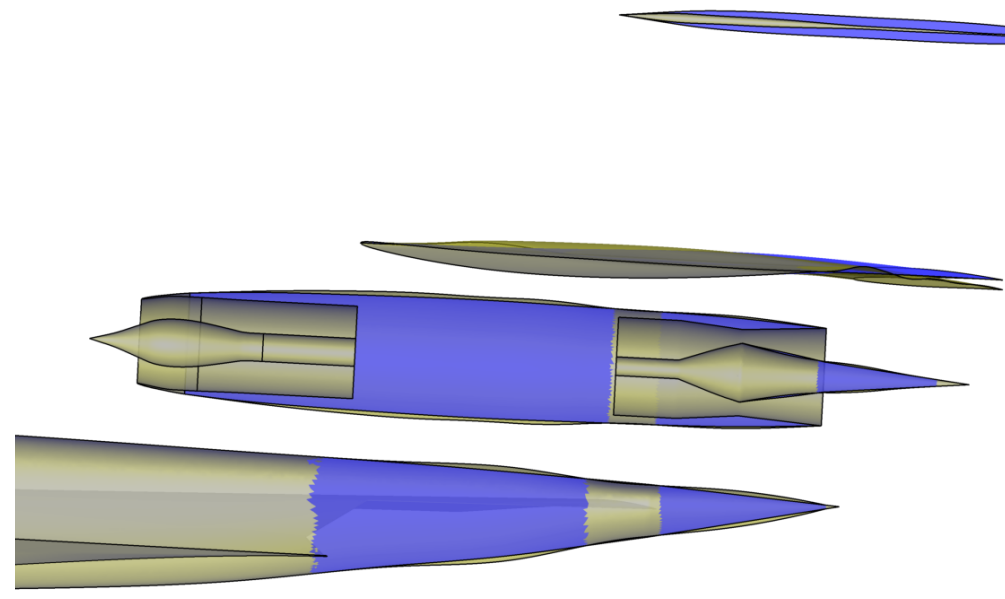

Figure 12. Baseline (blue) vs. low-boom optimized (yellow) component flow lines. 


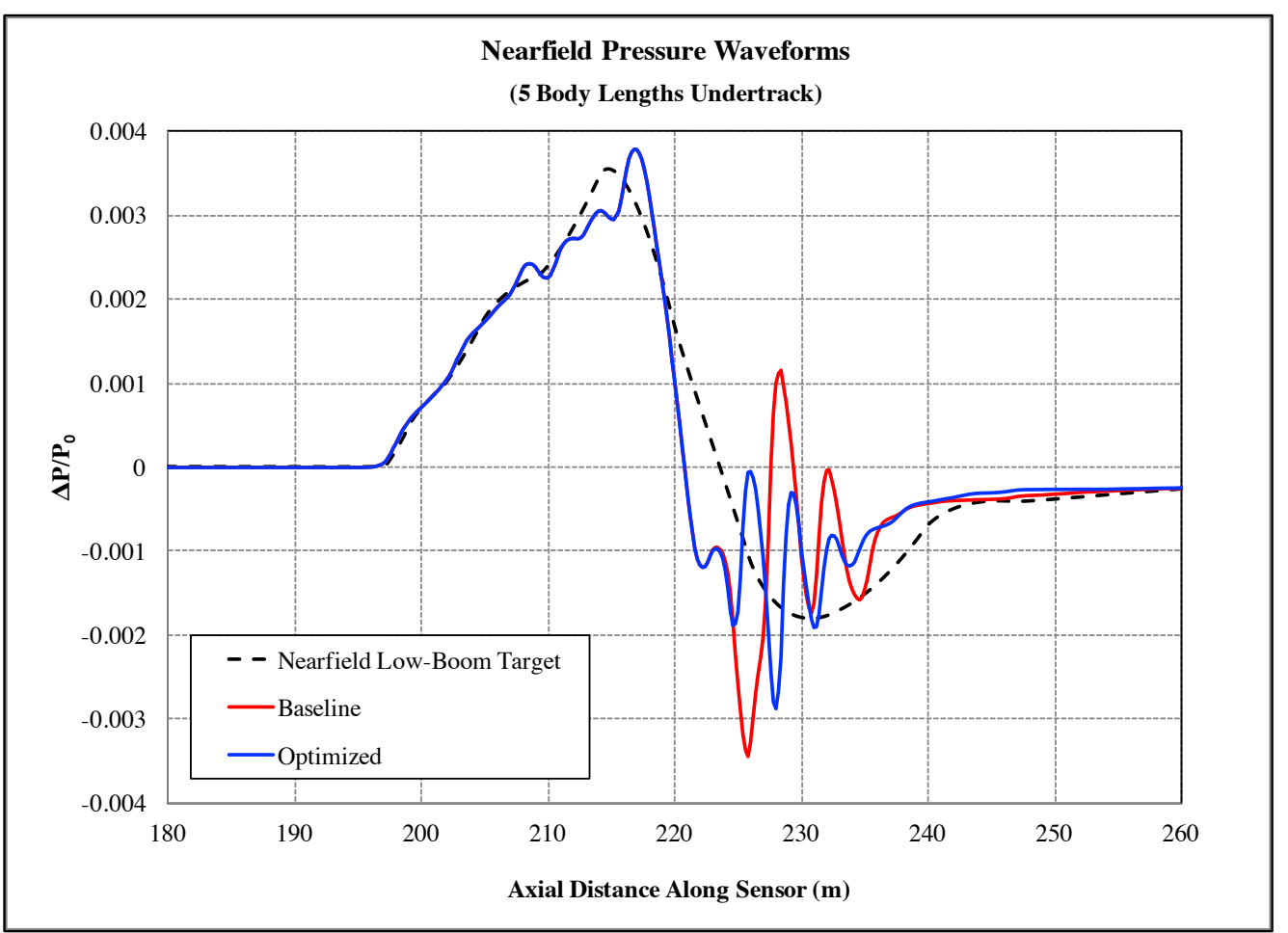

Figure 13. Comparison of near-field pressure waveforms for baseline and optimized aircraft.

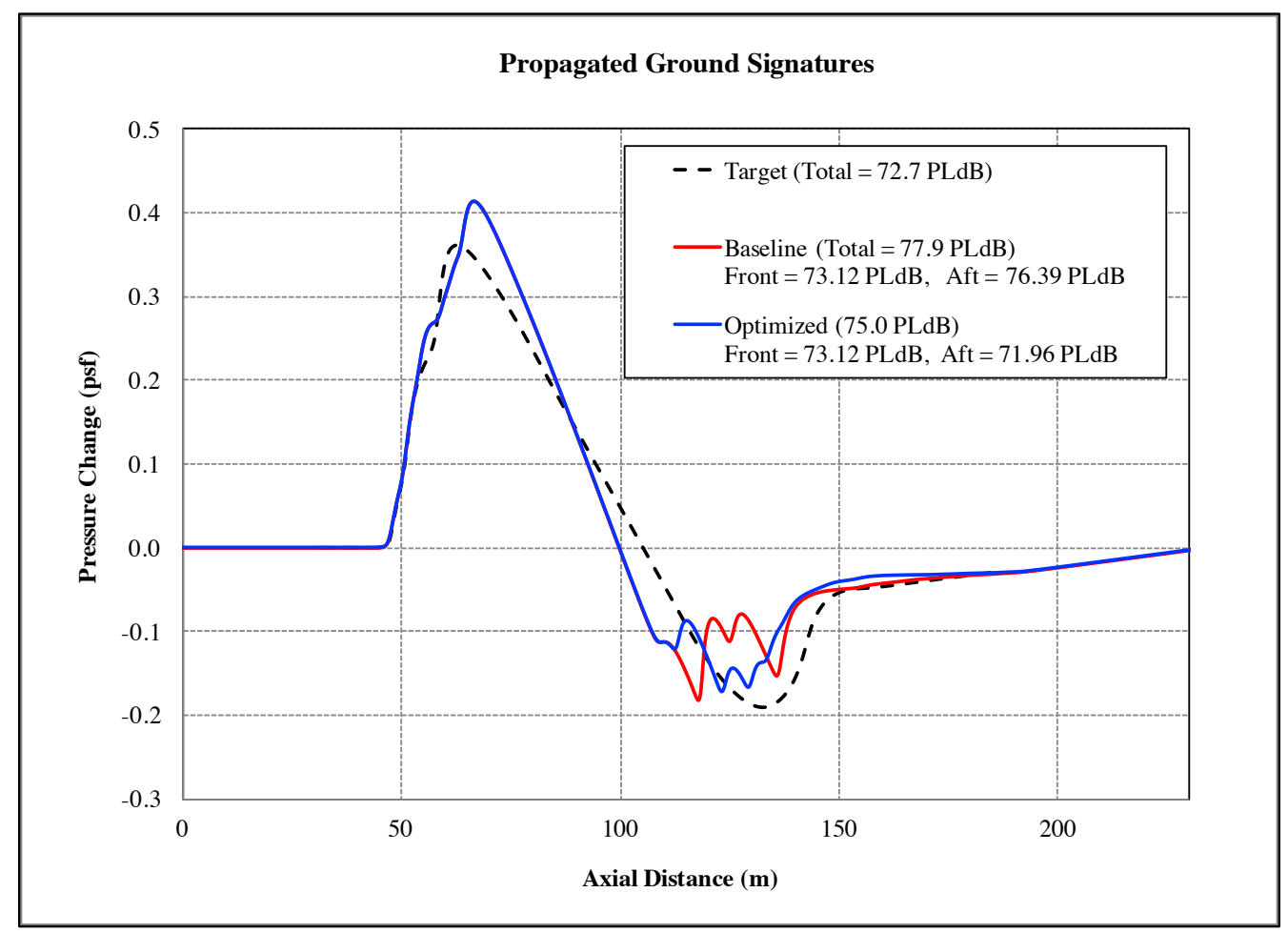

Figure 14. Comparison of propagated ground signatures for baseline and optimized aircraft. 

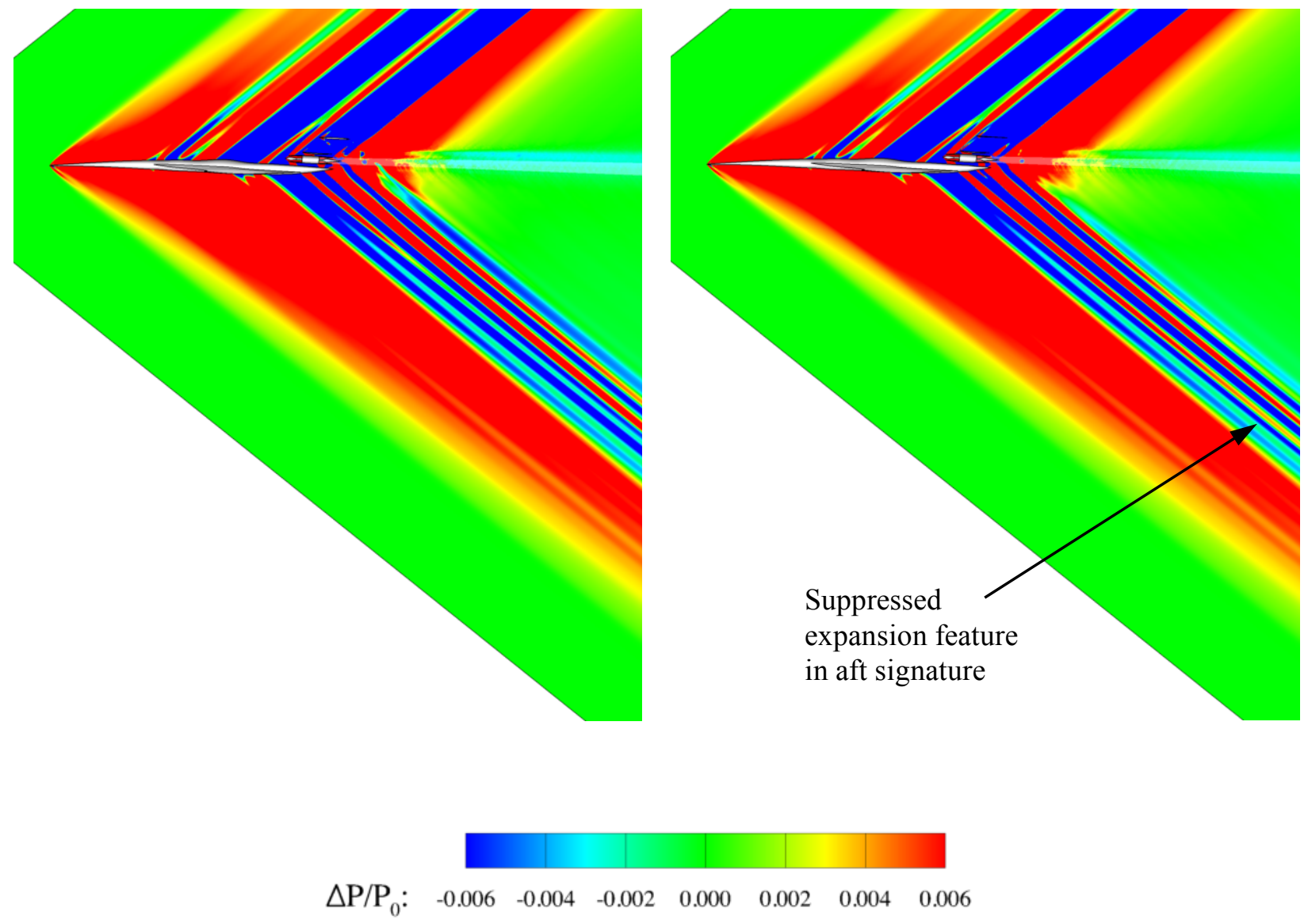

Figure 15. Baseline (Left) vs. low-boom optimized (Right) Mach number contour plots at cruise.

\section{Conclusions}

Ultra-low boom supersonic aircraft design calls for improved methods to reduce off-body pressure disturbances induced by propulsion airframe integration. To meet this need, adjoint-based optimization was demonstrated to tailor the aft signature of a low-boom aircraft concept with integrated propulsion system. The work enhances design fidelity over previous efforts by refining off-design inlet operation, incorporating a complete CFD-generated inlet performance map into the engine cycle model, and adjusting nozzle settings to be consistent with engine throttle at cruise. Each of these improvements helps to reduce uncertainty in the sonic boom loudness prediction due to the propulsion system, including nozzle plume and inlet spillage effects. In addition, the propulsion system is used to help reduce the aircraft sonic boom loudness, rather than relying on hidden or embedded engine installations that often degrade engine performance. The inlet redesign effort produced an installed inlet that adequately met engine demand throughout the entire flight envelope by leveraging auxiliary doors below Mach 0.6. Cruise inlet recovery performance was improved using aerodynamic shape optimization and increased by $\sim 1.8 \%$ at the cruise design point over a baseline design. The implementation of a flow bypass to redirect excess captured inlet flow at the cruise point was used to mitigate flow spillage and any potential resulting negative impact on sonic boom performance. The bypass also provides a buffer enabling inlet/engine airflow matching at cruise while achieving maximum inlet pressure recovery. Less than $2 \%$ inlet total pressure recovery is sacrificed at off-design operation around transonic due to the capture flow being mass limited. Inlet distortion was also found to be favorable with adequate distortion margin at all operating conditions within the flight envelope. Using the optimized inlet design, aerodynamic shape optimization of the engine nacelle, vertical tail fairing, horizontal tail, aft fuselage and nozzle plug surfaces was performed using 48 geometric control variables. The optimization yielded a 2.9 PLdB sonic boom reduction with $1.5 \%$ compromise in vehicle drag and $2.8 \%$ reduction is aircraft lift-to-drag ratio. While not insignificant, the levels of forced performance compromise are often necessary in the pursuit of optimal low-boom aircraft design. 
Many advancements can still be realized to push the boundaries on low sonic boom design. For example, additional low-boom margin of this reference configuration is likely achievable by also parameterizing and optimizing the forward fuselage and wing. Better ways to implement constraints, especially to help increase the liftto-drag ratio can also be explored. Methods to further reduce uncertainty of the final design configuration, including the use of adjoint-based grid adaptation methods to minimize discretization errors in the 3-D flowfield computations will be investigated in future work.

\section{Acknowledgements}

The authors gratefully acknowledge the Commercial Supersonic Technology project of the Fundamental Aeronautics Program for providing continued support for this research.

\section{References}

[1] Aftomis, M. J., Nemec, M., Cliff, S. E., “Adjoint-Based Low-Boom Design with Cart3D," In $29^{\text {th }}$ AIAA Applied Aerodynamics Conference, AIAA Paper 2011-3500, Honolulu, HI, June 27-30, 2011.

[2] Li, W., Rallabhandi, S., "Inverse Design of Low-Boom Supersonic Concepts Using Reversed EquivalentArea Targets," In $29^{\text {th }}$ AIAA Applied Aerodynamics Conference, AIAA Paper 2011-3498, Honolulu, HI, June 2730, 2011.

[3] Rallabhandi, S. K., Nielsen, E. J., Diskin, B., "Sonic-Boom Mitigation through Aircraft Design and Adjoint Methodology,” In Journal of Aircraft, Vol. 51, No. 2, pp. 502-510, 2014.

[4] Palacios, F., Alonso, J. J., Colonno, M., Hicken, J., Lukaczyk, T., "Adjoint-based Method for Supersonic Aircraft Design using Equivalent Area Distributions," In 50 ${ }^{\text {th }}$ AIAA Aerospace Sciences Meeting, AIAA Paper 2012-0269, Nashville, TN, January 9-12, 2012.

[5] Wintzer, M., Castner, R., "Aircraft-Nozzle-Plume Interactions in the Context of Low Sonic Boom Design," AIAA Science and Technology Exposition (SciTech), Manuscript Submitted for Publication, Kissimmee, FL, January 5-9, 2015.

[6] Conners, T. R., Henne, P.A., Howe, D. C. "A Method for Reducing Sonic Boom Strength by Tailoring the Shape of the Propulsive Streamtube," In $49^{\text {th }}$ AIAA/ASME/SAE/ASEE Joint Propulsion Conference, AIAA Paper 2013-3678, San Jose, CA, July 14-17, 2013.

[7] Heath, C. M., Slater, J., W., Rallabhandi, S., K., "Inlet Trade Study for a Low Boom Aircraft Demonstrator," In $34^{\text {th }}$ AIAA Applied Aerodynamics Conference, AIAA Paper 2016-4050, Washington, D.C., June 13-17, 2016.

[8] Conners, T., R., Wayman, T., R., "The Feasibility of High-Flow Nacelle Bypass for Low Sonic Boom Propulsion System Design," In $29^{\text {th }}$ AIAA Applied Aerodynamics Conference, AIAA Paper 2011-3797, Honolulu, HI, June 27-30, 2011.

[9] Rallabhandi, S., K., "Application of Adjoint Methodology in Various Aspects of Sonic Boom Design," In $32^{\text {nd }}$ AIAA Applied Aerodynamics Conference, AIAA Paper 2014-2271, Atlanta, GA, June 16-20, 2014.

[10] Biedron, R. T., Derlaga, J. M., Gnoffo, P. A., Hammond, D. P., Jones, W. T., Kleb, B., Lee-Rausch, E. M., Nielsen, E. J., Park, M. A., Rumsey, C.L., Thomas, J. L., Wood, W. A., "FUN3D Manual: 12.4," NASA TM-2014218179, 2014.

[11] Gill, P. E., Murray, W., and Saunders, M. A., "User's Guide for SNOPT Version 7: Software for LargeScale Nonlinear Programming," June, 2008.

[12] Marcum, D., "Generation of Unstructured Grids for Viscous Flow Applications," AIAA Paper No. 95-0212, AIAA, 1995.

[13] Park, M., Campbell, R., Elmiligui, A., Cliff, S., Nayani, S., "Specialized CFD Grid Generation Methods for Near-Field Sonic Boom Prediction," $52^{\text {nd }}$ Aerospace Sciences Meeting, No. AIAA 2014-0115, AIAA, National Harbor, MD, 2014.

[14] Cliff, S., Elmiligui, A., and Campbell, R., "Evaluation of Refined Tetrahedral Meshes with Projected, Stretched, and Sheared Prism Layers for Sonic Boom Analysis," $29^{\text {th }}$ AIAA Applied Aerodynamics Conference, Paper No. 2011-3338, AIAA, Honolulu, HI, 2011.

[15] Ordaz, I., Li, W., and Campbell, R., "Automated Tetrahedral Mesh Generation for CFD Analysis of Aircraft in Conceptual Design," 52 ${ }^{\text {nd }}$ Aerospace Sciences Meeting, Paper No. 2014-0118, AIAA, National Harbor, MD, 2014.

[16] Heath, C., Gray, J., Park, M., Nielsen, E., and Carlson, J-R., “Aerodynamic Shape Optimization of a DualStream Supersonic Plug Nozzle,” 53rd AIAA Aerospace Sciences Meeting, Paper AIAA 2015-1047, AIAA, Kissimmee, FL, 2015. 
[17] Samareh, J. A., "Multidisciplinary Aerodynamic-Structural Shape Optimization Using Deformation," AIAA/NASA/USAF/ISSMO Symposium on Multidisciplinary Analysis and Optimization; ${ }^{\text {th }}$; Paper AIAA 20004911, AIAA, Long Beach, CA, 2000.

[18] Samareh, J. A., "Aerodynamic Shape Optimization Based on Free-Form Deformation," AIAA/ISSMO Symposium on Multidisciplinary Analysis and Optimization; $10^{\text {th }}$; Paper AIAA 2004-4630, AIAA, Albany, NY, 2004.

[19] Roe, P. L., "Approximate Riemann Solvers, Parameter Vectors, and Difference Schemes," In Journal of Computational Physics, Vol. 43, Issue 2, pp. 357-72, October 1981.

[20] Spalart, P. R. and Allmaras, S. R., "A One-Equation Turbulence Model for Aerodynamic Flows," La Techerche Aerospatiale, No. 1, pp. 5-21,1994.

[21] Nielsen, E. J. and Anderson, W. K., "Recent Improvements in Aerodynamic Design Optimization on Unstructured Meshes," In AIAA Journal, Vol. 40, No. 6, pp. 1155-1163, 2002. See also AIAA Paper 2001-596.

[22] Nielsen, E. J., "Aerodynamic Design Sensitivities on an Unstructured Mesh Using the Navier-Stokes Equations and a Discrete Adjoint Formulation," Ph.D. Thesis, Virginia Polytechnic Institute and State University, 1998.

[23] Nielsen, E. J., and Diskin B., "Discrete Adjoint-Based Design for Unsteady Turbulent Flows on Dynamic Overset Unstructured Grids," AIAA Journal, Vol. 51, No. 6, pp. 1355-1373, June 2013.

[24] Giles, M., Duta, M., Müller, J.-D., and Pierce, N., "Algorithm Developments for Discrete Adjoint Methods," AIAA Journal, Vol. 41, No. 2, 2003, pp. 198-205, See also AIAA Paper 2001-2596.

[25] Nielsen , E. J., Lu, J., Park, M. A., and Darmofal, D. L., “An Implicit, Exact Dual Adjoint Solution Method for Turbulent Flows on Unstructured Grids," In Computers and Fluids, Vol. 33, No. 9, 2004, pp. 1131-1155, See also AIAA Paper 2003-272.

[26] Biedron, R. T., and Thomas, J. L., "Recent Enhancements to the FUN3D Flow Solver for Moving-Mesh Applications," AIAA-2009-1360, January 2009.

[27] Saad, Y. and Schultz, M. H., "GMRES: A Generalized Minimum Residual Algorithm for Solving Nonsymmetric Linear Systems," SIAM Journal of Scientific and Statistical Computing, Vol. 7, 1986, pp. 856-869.

[28] Slater, J., "Methodology for the Design of Streamline-Traced, External-Compression Inlets," AIAA Paper 2014-3593, AIAA, July, 2014.

[29] Rodriguez, D. L., "Multidisciplinary Optimization of a Supersonic Inlet Using a Cartesian CFD Method," AIAA/ISSMO Multidisciplinary Analysis and Optimization Conference; $10^{\text {th }}$, AIAA Paper 2004-4492, Albany, NY, 2004.

[30] Rodriguez, D. L., "Propulsion-Airframe Optimization on a Supersonic Business Jet," AIAA Aerospace Science Meeting and Exhibit; $45^{\text {th }}$, AIAA Paper 2007-1048, Reno, NV, 2007.

[31] Kline, H., "Adjoint-Based Optimization of a Hypersonic Inlet," AIAA Computational Fluid Dynamics Conference; $22^{\text {nd }}$, AIAA Paper 2015-3060, Dallas, TX, 2015.

[32] NASA, "NPSS User Guide: Rev. 1.6.5," Cleveland, OH, 2008.

[33] "GAO/NSIAD-96-98 Navy Aviation F/A-18E/F", U.S. General Accounting Office Report to Congressional Committees, June 1996.

[34] (Editor) Daly, M., “IHP Jane’s Aero Engines”, Issue 29, March 2011.

[35] Rallabhandi, S., "Advanced Sonic Boom Prediction Using the Augmented Burgers Equation," Journal of Aircraft, Vol. 48, No. 4, pp. 1245-1253, July-Aug. 2011. doi: 10.2514/1.C031248

[36] Shepherd, K. and Sullivan, B., "A Loudness Calculation Procedure Applied to Shaped Sonic Boom," NASA TP-3134, November 1991. 